\title{
CROPPING WITHOUT CULTIVATION AT RUKUHIA
}

\author{
F. B. THOMPSON \\ Rukuhia Soil Research Station, Hamilton
}

\begin{abstract}
Summary
Experiments are described in which choumoellier, soft turnips and swedes were drilled without cultivation into pasture which had been killed by paraquat or a mixture of 2,2-DPA and amitrole. Best results by the chemical method were from sowings two or four weeks earlier than sowings at the normal times on cultivated land. Yields of choumoellier and soft turnips on chemically treated plots ranged from $60 \%$ to $90 \%$ of those on cultivated plots. The swedes from normal sowings on cultivated land were very poor because the season was dry, whereas the chemical method gave good yields when used at the optimum times. Good yields of green-feed maize were obtained by the chemical method. Paraquat was slightly better than 2,2-DPA/amitrole.
\end{abstract}

\section{INTRODUCTION}

THE RESULTS of the earlier trials on cropping without cultivation conducted by the Department of Agriculture were summarized by Matthews (1959). Up to that time the chemicals used to destroy the turf were 2,2-DPA plus amitrole. Bramley (1961) gave results of trials with five new chemicals which had been tested and he concluded that paraquat appeared to be the most promising alternative to 2,2-DPA/amitrole mixture. This paper gives results of trials conducted at Rukuhia Soil Research Station. Hamilton, in 1961-62 in which paraquat and 2,2-DPA/amitrole were used to kill the turf before drilling in choumoellier, soft turnips and swedes. The object of the trials was to obtain more information about the factors which limit chemical methods of crop establishment, particularly with respect to paraquat which had not been used as extensively as 2,2-DPA/amitrole. Particular attention was paid to the effects of times of sowing using the chemical techniques. Results are also reported of trials with maize using the chemical method.

\section{EXPERIMENTAL}

Choumoellier (Medium Stem), soft turnips (York Globe) and swedes (Superlative) were drilled into cultivated plots and into pasture plots which had previously been sprayed with either paraquat at $1.8 \mathrm{lb}$, or a mixture of $7.4 \mathrm{lb}$ of 2,2-DPA plus $1 \mathrm{lb}$ of amitrole. The quantities of all chemicals are expressed as lb of active ingredient per acre. Wetting agent was used with the paraquat. The paraquat was applied to the pasture a few hours before drilling. The 2,2-DPA/amitrole mixture was usually applied two weeks before sowing, but out of a total of 17 applications five were three weeks before and one (January 9, 1962) was four weeks before. The chemicals were applied in 30 gal of water per acre at $30 \mathrm{lb} / \mathrm{sq}$. in. using an "Oxford" precision sprayer.

The crops were drilled at approximately two-weekly intervals from August to January using a coulter drill fitted with grassland tips. The swedes were sown at the rate of $1 \frac{1 / 2}{\mathrm{lb}}$ per acre in $14 \mathrm{in}$. 
drills and the choumoellier and soft turnips at $4 \mathrm{lb}$ and $1 \frac{1}{2} \mathrm{lb}$ per acre respectively in 7 in. drills.

The cultivated plots had been rotary-hoed previously and were raked by hand before drilling to kill weed seedlings. SMCA was used to control weeds on the choumoellier and soft turnips sown on September 14, 1961, and on the two sowings of swedes. The other crops on cultivated plots did not require spraying with SMCA Details of the sowing dates are given in Table 1.

The previous pasture consisted mainly of perennial ryegrass (Lolium perenne), cocksfoot (Dactylis glomerata) and white clover (Trifolium repens) with a small amount of browntop (Agrostis tenuis) and paspalum (Paspalum dilatatum). At the time of spraying in August, September and October, the pasture was approximately 2 in. high. At the later stages it was difficult to control the pasture and it averaged 4 or 5 in. high for the November, December and January sprayings. The application of 2,2-DPA/amitrole to the longer pasture in November and December resulted in a browny-green sward about 12 in. high at sowing time two or three weeks later. This long pasture was sprayed with paraquat at $0.9 \mathrm{lb}$ just before sowing.

The trials were conducted on Horotiu sandy loam. All treatments were randomized and there were four replications.

The crops were harvested and dry matters determined. Owing to the spread of sowing dates, the soft turnips matured at different times and it would have been unsatisfactory to harvest all crops at one time. The August and September sowings were harvested on January 16, 1962, the October 4,1961, sowing on January 25, 1962, and the last two sowings on March 1, 1962.

All the choumoellier plots were harvested on May 16-18, 1962, and the swedes on May 21 and 23, 1962.

In another series of trials, which commenced in November, 1961, maize (Wisconsin 575) was drilled, without cultivation, into a white clover dominant pasture containing a small percentage of mixed grasses. In one trial the sward had been sprayed the previous day with either paraquat at $0.9 \mathrm{lb}$ or $2,2-\mathrm{DPA}$ at $3.7 \mathrm{lb}$. Amitrole-T at $0.75 \mathrm{lb}$ was applied as a basal dressing. In another trial, paraquat at $0.225,0.45$, and $0.9 \mathrm{lb}$ was combined with amitrole- $\mathrm{T}$ at $0,0.375$ and $0.75 \mathrm{lb}$.

The maize was drilled to a depth of 3 to 4 in. with a chisel plough fitted with a fertilizer and seed box. The crop was harvested for green feed in February, 1962.

\section{RESULTS}

In general, the season was not good for crops because there were several long dry periods. There was only $0.2 \mathrm{in}$. of rain for 28 days in November and for seven weeks in January and February the total rainfall was only 1.75 in. Although heavy rain early in March saved the choumoellier crop, the rain came too late to enable good yields to be obtained. The failure of some of the late sowings of swedes, even on the cultivated plots, was probably largely due to the extremely dry conditions.

Details of the results of the brassica trials are given in Table 1. In Table 2 relative figures are given for the averages of the best three consecutive sowings of choumoellier and soft turnips by the chemical methods compared with the average results on the cultivated plots.

The sowing dates for the chemical method are two weeks earlier than those on the cultivated plots. The swede results are not included in Table 2 as the crops on the cultivated plots were sown later and were very poor owing to the dry season. 


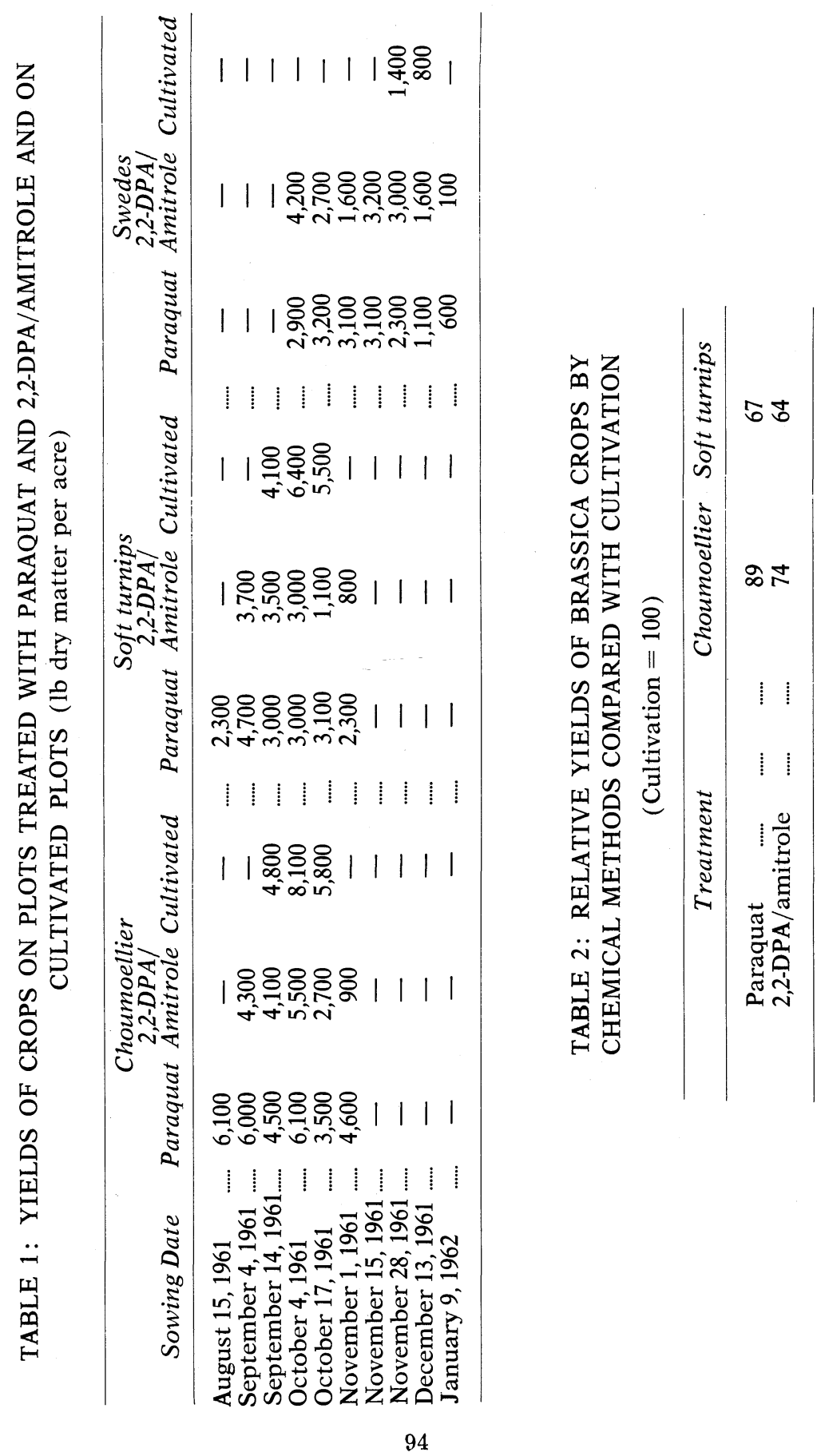




\section{PARAQUAT}

In general this gave a good kill of the ryegrass and cocksfoot in the previous sward. Paspalum, where present, survived, but there was so little of it that it did not seriously upset the trials. Some browntop survived, particularly in the sprayings later than September, but again there was not sufficient to upset the results. The white clover which survived on some of the paraquat plots tended to smother the crops. This smothering was particularly bad in the turnips, moderate in the swedes, but of no consequence in the choumoellier. In the turnips the smothering by white clover was most noticeable in the crops sown on August 15, September 14, and October 4, 1961. The turnips sown on September 4, 1961, did not suffer so badly and this was the best turnip crop on the paraquat plots. The yield was $89 \%$ of the average of the three sowings on cultivated plots. The plots where white clover smothering was worst were those where the pasture was shortest at the time of spraying (less than 2 in.) whereas on the other plots it was more than 2 in.

Drilling into the green sward on the paraquat plots was more difficult than into the dry pasture which had been sprayed with 2,2-DPA/amitrole.

\section{2,2-DPA/AMITROLE}

The kills of ryegrass were unexpectedly poor and decreased as the season advanced. The turnips on the 2,2-DPA/amitrole plots sown in mid-September and later were largely smothered by ryegrass. Similarly in the swede crops there was much surviving ryegrass which competed with the crops sown on October 17 and November 1, 1961. However, with the swedes sown on November 15, 1961, and later the grass was no problem because, as previously stated, the 2,2-DPA/ amitrole plots were sprayed with paraquat just before sowing, and this gave a complete kill of the grasses. This accounts for the higher yield of swedes on the 2,2-DPA/amitrole plots from the sowings on November 15 and 28,1961, compared with the poor yield from the sowing on November 1, 1961. In the choumoellier crop the competition from the grasses was not so serious. In general it is surprising that the 2,2-DPA/amitrole plots yielded so well in view of the competition from the grasses.

\section{Cultivated Plots}

The turnips and choumoellier sown on September 14, 1961, were badly infested with broadleaved weeds. SMCA applied on November 20,1961, reduced the willow weed (Polygonum persicaria) and redroot (Amaranthus hybridus) but there was land cress (Coronopus didymus) in the turnips and Chenopodium pumilio in the choumoellier which were more resistant to the SMCA. The two October sowings had a longer period of fallow after the last rotary-hoeing and the raking before sowing killed weed seedlings present. These two sowings remained relatively weed-free and did not require spraying with SMCA. The effect of the weed competition in the early stages of the crops sown on September 14, 1961, may partly explain why these sowings gave the lowest yields of the three sowings on cultivated plots with both crops.

\section{MaIze Trials}

Very good crops of green feed maize averaging 7 to $8 \mathrm{ft}$ in height and about 18 tons per acre green weight were obtained. As a result of the deep sowing with the chisel plough, there were no signs of residual effects of the 2,2-DPA or amitrole on the crop. Paraquat at $0.9 \mathrm{lb}$ was more effective than 2,2-DPA at $3.7 \mathrm{lb}$ in controlling the grasses, and the yields were slightly higher on the paraquat plots. 
The combination of paraquat at $0.45 \mathrm{lb}$ plus amitrole-T at $0.375 \mathrm{lb}$ gave a satisfactory kill of the grasses and sufficient suppression of the white clover.

\section{DISCUSSION AND CONCLUSIONS}

The main results from these trials are summarized as follows:

(1) The yields by the chemical technique were better when the materials were applied and the crops sown earlier in the season. This general statement applies to both paraquat and 2,2-DPA/ amitrole in all three crops. The high swede yields on the 2,2-DPA/ amitrole plots sown on November 15 and 28,1961 , are two outstanding apparent anomalies, but these are explained by the good kill of the grasses owing to the paraquat applied just good kill of the grasses owing to the paraquat applied just 2,2-DPA/amitrole alone to kill the grasses at the sowing on November 1,1961 . The optimum time for the chemical method appears to be two or four weeks earlier than the normal sowing time on cultivated land.

(2) Paraquat gave slightly better yields than 2,2-DPA/amitrole. The marked difference in favour of paraquat in all three crops sown on November 1, 1961, is exceptional. At this sowing the pasture on the paraquat plots was 6 in. high whereas on the 2,2-DPA/ amitrole plots it was only 2 to 3 in. when these were sprayed two weeks previously. The long growth on the paraquat plots would act as a mulch during the very dry spell in the following four weeks whereas the 2,2-DPA/amitrole plots would not have this advantage. This difference did not apply to the swedes sown on November 15, 1961, and subsequently, because at these later sowings the growth was long on both the paraquat and 2,2-DPA/ amitrole plots.

(3) The success of the chemical methods with maize is largely due to the fact that suitable equipment was available to sow the maize at sufficient depth in the sward. By sowing deeply, the risk of residual toxicity from the chemicals was reduced and the crop was better able to withstand the subsequent dry weather.

(4) The results confirm that the chemical method in general and paraquat in particular has considerable promise. In view of results obtained in grass tolerance trials (Thompson, 1962), the rate of paraquat could be reduced, provided resistant grasses were not present to any appreciable extent. However, further experimental work is desirable to determine more precisely the factors which limit crop production by the chemical method and the conditions under which each chemical can be used to greatest advantage.

\section{ACKNOWLEDGEMENT}

The assistance of members of the staff of the Weed Section, Rukuhia Soil Research Station, and the Biometrics Station, Department of Agriculture, Wellington, is gratefully acknowledged.

\section{REFERENCES}

Bramley, P. 1961 : Proc. 14th N.Z. Weed Control Conf., p. 41.

Matthews, L. J. 1959: Proc. 12 N.Z. Weed Control Conf., p. 43

Thompson, F. B. 1962: Proc. 15th N.Z. Weed Control Conf., p. 190. 